The Englishization of Higher

Education in Europe 



\title{
The Englishization of Higher Education in Europe
}

\author{
Edited by \\ Robert Wilkinson and \\ René Gabriëls
}


Cover image: Robert Wilkinson

Cover design: Coördesign, Leiden

Typesetting: Crius Group, Hulshout

ISBN $\quad 9789463727358$

e-ISBN 9789048553914 (pdf)

DOI $\quad 10.5117 / 978946372735^{8}$

NUR 133

\section{(C) (1) $\Theta \Theta$}

Creative Commons License CC BY NC ND (http://creativecommons.org/licenses/by-nc-nd/3.o)

@ All authors / Amsterdam University Press B.V., Amsterdam 2021

Some rights reserved. Without limiting the rights under copyright reserved above, any part of this book may be reproduced, stored in or introduced into a retrieval system, or transmitted, in any form or by any means (electronic, mechanical, photocopying, recording or otherwise). 